\title{
Historia de la regeneración constitucional de $1886^{*}$
}

\author{
History of the Constitutional \\ Regeneration of 1886
}

\section{Hernán Alejandro Olano García**}

\section{RESUMEN}

El autor, dentro de su linea de investigación en historia de las instituciones, presenta un análisis de la Constitución colombiana de 1886, que antecedió en su época a la Carta de Querétaro de 1917. Dicha carta colombiana se expidió en el marco del movimiento regeneracionista, que buscaba seguir impidiendo la hecatombe politica causada por el liberalismo radical colombiano, que habia llevado al país a veintidós años continuos de guerra civil, en un derramamiento fratricida de sangre. Se busca, con este artículo, aportar luces al conocimiento de una constitución centenaria, reemplazada en 1991 por una Carta garantista y pluralista.

PALABRAS CLAVE: Constitución, regeneración, estado, democracia, liberalismo, conservatismo, guerra civil.

\begin{abstract}
The author, within the line of his research in the History of Institutions, presents an analysis of the Colombian Constitution of 1886, which preceded the 1910 Letter of Querétaro. This Colombian letter was issued within the framework of the regenerationist movement, which sought to continue to prevent the political hecatomb caused by radical Colombian liberalism, which had led the Country to twenty-two continuous years of Civil War, in a fratricidal bloodshed. With this article, it is sought to contribute shed lights to the knowledge of a Centennial Constitution, replaced in 1991 by a Guarantee and Pluralist Charter.
\end{abstract}

KEY WORDS: Constitution, Regeneration, State, Democracy, Liberalism, Conservatism, Civil War.

\footnotetext{
* Artículo de investigación. Recibido el 15 de julio de 2017 y aceptado para su publicación el 19 de junio de 2018.

** Profesor de la Escuela de Cadetes de Policía "General Francisco de Paula Santander" y de la Universidad Militar "Nueva Granada", campus Cajicá, Colombia. (hernan.olano@unisabana.edu.co) orcid.org/0000-0001-7662-4504
} 
La ancestral Carta colombiana de 1886, también denominada como la Constitución de Núñez y Caro, en alusión a sus progenitores naturales, parecía no tener posibilidades de cambio. Al dejar de existir en 1991, la Constitución de Querétaro de 1917, que por entonces era la que le sucedía en antigüedad, quedó como la decana del constitucionalismo latinoamericano. Por esta razón, siguiendo con el método histórico, citaremos algunos antecedentes de la Constitución colombiana de 1886 para mostrar el influjo de la regeneración en el nacimiento de la República de Colombia, al retomarse ese nombre que tuvo el país entre 1819 y 1830. El objeto de estudio es describir esta Constitución, con base en una metodología de relato, que sustenta nuestra forma de presentarla.

Lógicamente, la Regeneración no podía tener vida mientras subsistiera la Carta de 1863. Fue así como se sucedió otra guerra civil entre enero y julio de 1885, promovida por el liberalismo radical para derrocar el gobierno de Rafael Núñez, iniciada con la toma del río Magdalena en su paso por Santander y extendida rápidamente a Cundinamarca y Boyacá. Pero, con el combate de La Humareda, el 17 de junio de 1885, el ejército radical, comandado por los generales Gabriel Vargas Santos, Ricardo Gaitán Obeso y Daniel Hernández, fue completamente derrotado. Así, se sellaría el último episodio sangriento de la Carta del 63 y se abriría las puertas a la Carta de 1886.

Rafael Núñez Moledo, insigne poeta y estadista, "Ya desde 1875 y en su calidad de candidato presidencial [...] tenía claro que era preciso reformar el sistema político vigente para que el país superara el desorden y la violencia, y esto requería un sistema político en el que el Estado fuera vigoroso". ${ }^{1}$

Luego de la guerra de $1885^{2}$ entre los radicales y los regeneracionistas de Núñez, se vio el triunfo de la regeneración, cuyos partidarios anhelaron encauzar el destino de la nación por el camino del orden, contra la anarquía y las guerras civiles. Para ello, "Núñez entregó el control de la guardia nacional a generales conservadores, lo que indicaba a sus copartidarios que estaba dispuesto a abandonar el barco liberal". ${ }^{3}$ Se criticó el estado anárquico del país, reflejado en las constantes guerras civiles, la multiplicidad de constituciones, la miseria de la mayoría de colombianos, el atraso en la industria y en la agricultura y el estancamiento de la nación. Se criticó por entonces también el espíritu de libertad excesiva que la Constitución de Rionegro imprimió en las instituciones; la debilidad del ejecutivo, la libertad de expresión irresponsable y la desorganización del sistema penal.

1 López Medina, Diego Eduardo, El Derecho de los Jueces, Bogotá, Legis - Universidad de los Andes, 2006, p. 7.

2 España, Gonzalo, La guerra civil de 1885. Núñez y la derrota del radicalismo, Bogotá, El Áncora Editores, 1985, p. 12.

${ }^{3}$ Melo, Jorge Orlando, Historia mínima de Colombia, México, El Colegio de México - Turner, 2017, p. 167. 
Victorioso el presidente Núñez en la guerra, quien se erigió en verdugo del liberalismo radical, con la ayuda del partido conservador y de su jefe Leonardo Canal, anunció ante la multitud "La Constitución de Rionegro ha dejado de existir". El 10 de septiembre de 1885 convocó al Consejo Nacional de Delegatarios para que deliberara sobre los términos en los cuales debería procederse a la reforma constitucional y para deliberar acerca de los términos en que debía procederse a expedir la nueva constitución. Sus integrantes, designados a dedo por Núñez, no fueron elegidos popularmente. Se autorizó a los estados soberanos para que designaran, por cada uno, dos delegatarios: uno liberal independiente y otro conservador, para expedir la reforma constitucional.

A mi juicio, se procedió con criterio discriminatorio al integrar la representación de Antioquia, Cauca y Panamá, estados reconocidamente federalistas. Como consecuencia, no hubo delegatarios naturales de esos estados en el cuerpo constituyente. Asimismo, por medio del Decreto 594 del 10 de septiembre de $1885,{ }^{4}$ el presidente de los Estados Unidos de Colombia consideró necesario promover el restablecimiento del régimen constitucional, desorganizado por la rebelión. Tomó en cuenta, también, las manifestaciones escritas de la opinión pública, a la vez que los antecedentes de la constitución que debía ser reemplazada. Por lo tanto, decretó que los gobiernos de los estados enviasen delegatarios a un consejo nacional en razón de dos principales y tres suplentes numerados para cada uno de éstos. Finalmente, el 11 de noviembre de 1885, se instaló el Consejo Nacional de Delegatarios, integrado por dieciocho representantes principales a razón de dos por cada Estado, más los suplentes numerados, atendiendo, como se dijo, la paridad política entre conservadores y liberales.

El presidente Núñez, conocido también como "el hombre del cabrero", pronunció un sentido discurso, "considerado como el documento más interesante y digno de fama de cuantos han pronunciado nuestros presidentes, desde que desapareció el Libertador". ${ }^{5}$ En ellas quiso hacer notar al existencia de un nuevo pacto institucional para poner clausura al período anterior, que, según él, había "dejando tras de sí prolongada estela de desgracias". Lo anterior dado que en esos más de veinte años, tanto el comercio de armas y de municiones, la incesante guerra civil entre las regiones, así como los asesinatos y las masacres colectivas, deberían llegar a su fin, lo mismo que el uso indiscriminado de la imprenta, que debería ser antorcha de cordialidad y no de terror y calumnia. ${ }^{6}$

Sin embargo, no resultó fácil hacer la transición del sistema federal al central. El federalismo, pese a sus exageraciones, se había practicado durante un cuarto

\footnotetext{
${ }^{4}$ Valderrama Andrade, Carlos, Miguel Antonio Caro y la Regeneración, Bogotá, Instituto Caro y Cuervo, 1997, pp. 21-26

${ }^{5}$ Acevedo Restrepo, Delfin, La Constitución Nacional y sus principales reformas, Bogotá, EsAP, 1986, p. 13.

${ }^{6}$ Acevedo Restrepo, Delini, La Constitución Nacional y sus principales reformas, Bogotá, ESAP, 1986, p. 13.
} 
de siglo, en el cual, según el delegatario Carlos Calderón "se habían educado tres generaciones". El territorio colombiano, parcelado en tres grandes cordilleras, era adecuado al sistema federal, que, además, había consolidado hegemonías políticas y económicas, muy difíciles de desarraigar. Tanta penetración había logrado en Colombia el sistema federal que los tres proyectos presentados, al iniciarse las deliberaciones del Consejo Nacional de Delegatarios, se resentían, en mayor o menor grado, de veleidades federalistas. El de José María Samper, titulado "Pacto de Unión de los Estados", revivía algunas normas de la Carta de Rionegro, consagrando el principio de la unidad nacional y cuidando de preservar para los Estados la descentralización administrativa y municipal. El proyecto del general Rafael Reyes, escrito por don Sergio Arboleda, trataba de armonizar la fórmula federal con la central; y el del delegatario José Domingo Ospina Camacho mantenía el régimen federal con enmiendas importantes a la Carta de 1863.

Por su parte, como delegatario por Panamá, el conservador Miguel Antonio Caro, "centralista irrevocable", hizo parte del Congreso y fue uno de los más destacados constituyentes. "Su pasión fue el catolicismo en la política, e inclusive llegó a proponer un partido católico para restaurar el orden civil de los cristianos, si el conservatismo se llegase a civilizar." Se le recuerda por la redacción de las bases de reforma, sometidas a consideración de las municipalidades para que las aprobaran, lo cual se logró con el voto afirmativo de 605 contra 14 de los concejos municipales. Luego de aprobadas por el Poder Ejecutivo, quedaron descartados los tres proyectos iniciales presentados al comienzo de las deliberaciones. Tales bases fueron dadas desde el 30 de noviembre de 1885, considerando que era de urgente necesidad hacer conocer a la República el espíritu que dominaba al Consejo Nacional de Delegatarios en sus deliberaciones relativas a la reforma constitucional, expidiendo al efecto una propuesta y fijando la tramitación con arreglo a las cuales habría de formarse y expedirse la nueva Constitución de Colombia. ${ }^{8}$

Artículo $1^{\circ}$. El Consejo Nacional de Delegatarios ejercerá las funciones de Cuerpo Constituyente, y el acto constitutivo que conforme a estas bases expida, si fuere sancionado por el Poder Ejecutivo, tendrá una vez publicado la fuerza permanente de cata fundamental o Constitución de la república.

Ocampo López, Javier, ¿Qué es el Conservatismo Colombiano? Bogotá, Planeta, 1991, p. 102.

${ }^{8}$ Antecedentes de la Constitución Colombiana de 1886. Tomo VIII Complementario de la Historia Extensa de Colombia, Academia Colombiana de Historia, Bogotá, Plaza y Janés, 1988. 
Artículo $2^{\circ}$. Tan luego como sea sancionada y publicada la Constitución, el Consejo Nacional de Delegatarios ejercerá las siguientes funciones: 1. Todas las de carácter legislativo que sean propias del Congreso;

2. Todas las relativas a nombramientos que deban hacer o aprobar las Cámaras separadamente, o el Congreso en Cámaras reunidas; y

3. Elegir libremente para el primer período constitucional el Presidente y el Vicepresidente de la República.

Artículo $3^{\circ}$. El presente Acuerdo no tendrá fuerza obligatoria sino después de haber sido sancionado por el Poder Ejecutivo y aprobado por el pueblo colombiano. Corresponde al Poder Ejecutivo expedir los decretos necesarios para disponer el modo y términos en que deba consultarse, a la mayor brevedad posible, la voluntad de la nación. ${ }^{9}$

Y continuaban así:

a. La soberanía reside única y exclusivamente en la Nación, que se denominará República de Colombia.

b. Los estados o secciones en que se dividía el territorio nacional tendrán amplias facultades municipales, y las demás que fueren necesarias para atender al desarrollo de sus peculiares intereses y adelantamiento interno.

c. La conservación del orden general y seccional corresponde a la Nación. Sólo ella puede tener ejército y elementos de guerra, sin perjuicio de los ramos de policía que corresponden a las secciones.

d. La legislación civil, penal, electoral, de minas, de organización y procedimiento judicial, es de competencia exclusiva de la Nación.

e. La instrucción pública oficial será reglamentada por el gobierno nacional, y gratuita, pero no obligatoria.

f. La Nación reconoce que la Religión Católica es la de la casi totalidad de los colombianos, principalmente para los siguientes fines:

- Estatuir que la Iglesia Católica gozará de personería jurídica.

- Organizar y dirigir la educación pública en consonancia con el sentimiento religioso del país.

${ }_{9}$ Pombo, Manuel y Guerra, José Joaquin, Constituciones de Colombia, tomo 4, Colombia, Fondo de Promoción de la Cultura del Banco Popular, 1986, pp. 195-196. 
- Celebrar convenios con la Santa Sede Apostólica, a fin de arreglar las cuestiones pendientes, definir y establecer las relaciones entre la potestad civil y la eclesiástica.

g. Será permitido el ejercicio de todos los cultos que no sean contrarios a la moral cristiana y a las leyes.

Los actos que se ejecuten con ocasión o pretexto del ejercicio de los cultos estarán sometidos al derecho común.

h. Nadie será molestado por sus opiniones políticas, ni obligado por autoridad alguna a profesar creencias ni a observar prácticas contrarias a su conciencia.

i. La prensa será libre en tiempo de paz, pero estará sujeta a responsabilidad cuando atente contra la honra de las personas o contra el orden social, o contra la tranquilidad pública.

j. Las demás libertades individuales serán consignadas en la Constitución con razonables limitaciones.

k. No podrá imponerse la pena de muerte sino en los casos de graves delitos militares y de delitos comunes atroces.

1. El Senado será constituido de tal manera que asegure la estabilidad de las instituciones, y la Cámara de Representantes, como cuerpo representativo del pueblo colombiano. Para ser Senador o Representante se necesitan condiciones especiales, pero no unas mismas, de elegibilidad. El Senado se renovará parcialmente, y los senadores funcionarán por seis años. La Cámara de representantes se renovará en su totalidad y dentro del término más breve.

m. El Presidente de la República será elegido para un período de seis años. Será reemplazado, llegado el caso, por un funcionario llamado Vicepresidente, quien será elegido por los mismos electores, al mismo tiempo y por igual período que el presidente.

n. El Poder Ejecutivo tendrá derecho a objetar proyectos de ley. En caso de insistencia del Congreso, será necesario el voto de las dos terceras partes de los miembros presentes en cada Cámara para que el Poder Ejecutivo deba dar sanción al proyecto objetado.

o. Por regla general los agentes del Poder Ejecutivo serán de su libre nombramiento y remoción.

p. Se establecerá una Alta Corporación llamada Consejo Nacional o Consejo de Estado, con funciones principalmente de cuerpo consultor y encargado de contribuir a la preparación de las leyes, de formar la jurisprudencia política de la Nación, y de conmutar la pena capital.

q. El Poder Judicial será independiente. Los Magistrados de la Corte Suprema de Justicia durarán en sus puestos todo el tiempo de su buena 
conducta, y serán responsables por los abusos que cometan en el ejercicio de su ministerio.

r. El Poder Electoral será organizado como Poder independiente.

En diciembre de 1885, se eligió por parte del Consejo Nacional de Delegatarios como presidente de la república a don Rafael Wenceslao Núñez Moledo, para la vicepresidencia a Eliseo Payán y como designado al general José María Campo Serrano. Este último también hacía parte del Congreso y, con diecisiete consejeros delegatarios, sancionó la Constitución el 5 de agosto de 1886, dos días antes de lo previsto, pues el presidente Núñez, que estaba de regreso de Cartagena tenía previsto hacerlo el día 7, para celebrar así los 67 años de la independencia absoluta de Colombia. La Constitución de la República de Colombia sería entonces un estatuto verdaderamente nacional por el acuerdo tácito de todos los colombianos.

En la Constitución de 1886, "centralista, hispánica y confesional", ${ }^{10}$ se pueden apreciar cuatro rasgos fundamentales: "Unidad nacional, libertad religiosa, derechos para todos, estabilidad y autoridad", que corresponden a la siguiente explicación.

- Libertad de la Iglesia católica, la cual fue reconocida como esencial elemento del orden social, aunque se reconocieron los demás cultos que no fueran contrarios al orden público o a la moral.

- Libertades individuales prácticas y bien definidas. Al establecer los derechos del hombre, consignó también los deberes del ciudadano y las garantías sociales

- Restablecimiento de la unidad nacional, pues se expidió la Carta declarando que la soberanía residía esencialmente en la nación.

- Robustecimiento del principio de autoridad. Pues para afianzar al ejecutivo, le otorgó un período presidencial de seis años.

- También pueden tenerse en cuenta como características de esta Constitución, los que resumió el propio Núñez en la siguiente fórmula: "Unidad Nacional, Libertad religiosa, derechos para todos, estabilidad y Autoridad". ${ }^{11}$

\footnotetext{
${ }^{10}$ Ceballos Gómez, Diana, Desde la formación de la República hasta el Radicalismo Liberal (1830-1886), en Luis Enrique Rodríguez, Ricardo Arias, Carlos Uribe, Ana Laura Rodríquez, et al., Historia de Colombia. Todo lo que hay que saber, Bogotá, Taurus, 2010, p. 167.

${ }^{11}$ Ocampo López, Javier, ¿Qué es el Conservatismo Colombiano? Bogotá, Planeta, 1991, p. 103.
} 
Adicionalmente, de esta Constitución se rescata el que de ella se mantienen incólumes, incluso en la actual Constitución de 1991, la República Unitaria. Los estados que constituían la unión llevan el nombre de departamentos, y la ley puede decretar bajo ciertas condiciones la formación de otros nuevos. El poder presidencial se revitalizó y, reanudando la vocación nacional que había sido interrumpida en 1863, invocó nuevamente en el preámbulo el nombre de la Divina Providencia como fuente suprema de toda autoridad. Se dio a la nación el nombre de República de Colombia, organizándola en forma democrática. Se limitó el voto a la capacidad económica y al alfabetismo, permitiendo que únicamente los ciudadanos eligieran en forma directa los concejos municipales y las asambleas departamentales. A través de compromisarios, se elegía a los representantes a la Cámara.

Se buscó el entendimiento y la mutua colaboración entre la Iglesia y el Estado y, para devolverle "a la Iglesia el poder perdido, siguiendo la nueva convicción de Núñez sobre la importancia de la religión para el orden público", ${ }^{12}$ se declaró que la religión católica era la religión oficial. ${ }^{13}$ Por tanto, es la de la nación y por tanto, los poderes públicos la protegerán y harán que sea respetada como esencial elemento del orden social. Empero, "la Iglesia no es, ni será oficial y conservará su independencia”. La educación pública fue organizada y dirigida en concordancia con la religión católica, poniéndola bajo su tutela; se toleraban los cultos no contrarios a la moral cristiana ni a las leyes. Las relaciones entre la potestad civil y la eclesiástica se regularían por convenios con la Santa Sede. Lo anterior se hizo efectivo el año siguiente, cuando nuestra nación designó como su plenipotenciario ante la Santa Sede a Joaquín Fernando Vélez, quien procedió en 1887, el 31 de diciembre, a firmar con el secretario de León XIII, el cardenal Rampolla, el Concordato con la Santa Sede, adicionado en 1892, para devolver a la Iglesia la administración de los cementerios y el registro de nacimientos y defunciones. Con ello, se privilegió hasta 1939 los actos eclesiásticos sobre los civiles.

Se consagró, además, la prensa libre en tiempo de paz, pero responsable cuando atentara contra la honra de las personas, el orden social o la tranquilidad pública. El presidente de la República nombraba y removía libremente a los gobernadores de los departamentos, que son agentes del gobierno central. En los casos de guerra exterior o de conmoción interior, el ejecutivo quedaba

\footnotetext{
${ }^{12}$ Melo, Jorge Orlando, Historia mínima de Colombia, México, El Colegio de México - Turner, 2017, p. 167.

${ }^{13}$ Véase sobre el particular la Sentencia C-350 de agosto 4 de 1994, Corte Constitucional, sobre la Consagración de la República de Colombia al Sagrado Corazón de Jesús y la Sentencia C-027 del 14 de febrero de 1993, acerca de la inexequibilidad parcial del Concordato entre Colombia y la Santa Sede.
} 
investido, mediante algunas formalidades, de facultades extraordinarias; el territorio de la República se dividió en Departamentos y estos en municipios.

La Función Legislativa la ejercían dos Cámaras de Senadores y de Representantes. Estas se reúnen cada dos años, el 20 de julio, durante ciento cincuenta días; el congreso formado por el senado y la cámara de representantes, elegidos a razón de tres senadores por cada departamento y un representante por cada 50000 habitantes, tenía un período de 6 y 4 años respectivamente. El presidente era el elegido por las asambleas electorales para un período de seis años y sus atribuciones tendían a darle más fuerza al ejecutivo. La Constitución podía ser reformada por dos legislaturas sucesivas y por el voto, en la última, de las dos terceras partes de los congresistas. ${ }^{14}$

El Ejecutivo lo ejercía el presidente de la República, junto con los ministros del Despacho y los Jefes de los Departamentos Administrativos. El presidente tenía el poder de nombrar a los gobernadores de los departamentos. Existía también la figura del designado, elegido cada dos años por el Congreso para reemplazar al presidente. Por último, la Función Judicial la ejercía la Corte Suprema de Justicia, el Consejo de Estado, los tribunales y los jueces, aunque todos debían ser designados por el gobierno.

Con la regeneración se regresó a la organización político-administrativa centralista, lo cual incluyó la creación de un ejército nacional (en cuyo proyecto se unen la fracción liberal de Núñez con la conservadora de Caro contra los radicalismos liberal y conservador), que se impone constitucionalmente después de la derrota militar del federalismo.

Aunque la Constitución de 1886 se consideraba como un documento de consenso, en uso de los artículos transitorios fueron expedidas varias disposiciones restrictivas, que transformaron el recién creado Estado de derecho en un Estado policía. ${ }^{15}$

a. El artículo transitorio K que disponía: "Mientras no se expida la Ley de Imprenta, el gobierno queda facultado para prevenir y reprimir los abusos de la prensa. Esta norma dejaba en libertad al gobierno para prohibir las publicaciones que no fueran de su gusto y para establecer la censura previa e ilimitada.

b. El Decreto \#151 del 17 de febrero de 1888, dictado por el gobierno en ejercicio de las facultades conferidas por el artículo transitorio K, que dividió las infracciones de prensa en delitos y culpas contra la sociedad

\footnotetext{
${ }^{14}$ Garcia Valencia, Julio César, Historia de Colombia, Colombia, Asamblea Departamental de Antioquia, 1994, p.191.

${ }^{15}$ Rivadeneira Vargas, Antonio José, Historia Constitucional de Colombia 1510-1978, Bogotá, Horizontes, 1978, pp. 138140.
} 
y contra los particulares, definiendo como publicaciones subversivas las que dañan o alarman a la sociedad y calificó como ofensivas a las que vulneran los derechos individuales.

c. La Ley 61 de 1888, conocida como "Ley de los Caballos, que permitía al Gobierno prevenir y reprimir administrativamente sin necesidad de juicio de los delitos y culpas que afectaran el orden público o el derecho de propiedad, e imponer las penas de confinamiento, expulsión del territorio, prisión y pérdida de los derechos políticos. Sirvió de pretexto para la expedición de dicha ley una ola de bandolerismo que se desató en ciertas regiones del país, que entre sus excesos de crueldad inútil llegó hasta desjarretar los caballos que no podían robarse. De allí el nombre de "Ley de los Caballos", dado por don Fidel Cano en $E l$ Espectador de Medellín.

d. La Ley 153 de 1888, cuyo artículo 6 consagró el principio de que toda ley se presumía constitucional y se aplicaba aun cuando pareciera contraria a la Constitución.

Se agrega la relación completa de los actos reformatorios de la Constitución de 1886, para notar los vaivenes de la Carta, dependiendo de las circunstancias políticas que rodearon la continuidad de la hegemonía conservadora hasta 1930; la segunda república liberal hasta 1946; La violencia hasta 1958; el Frente Nacional hasta 1974 y, luego, diecisiete años de ajuste institucional bipartidista: ${ }^{16}$

La primera reforma que sufrió la Constitución de 1886 se realizó a través de la ley 41 de 1894, en la cual se dispuso derogar el artículo 201 de la Carta y el ordinal 4 del artículo 76. En consecuencia, el Departamento de Panamá quedó comprendido en la legislación general de la República, pudiendo dictarse disposiciones legislativas y ejecutivas especiales para dicho Departamento.

La segunda enmienda fue por Ley 24 de 1898, que sustituyó el artículo 205 de la codificación original.

El acto reformatorio 01 de 27 de marzo de 1905 estableció un período de cinco años para los magistrados de la Corte Suprema de Justicia y de cuatro para los de los Tribunales Superiores, quienes por una sola vez fueron nombrados en su totalidad por el presidente de la República para el período que se iniciaba el 1 de mayo de 1905.

Por otro lado, el acto reformatorio 02, del 28 de marzo de 1905, estableció la reunión de las cámaras por derecho propio cada año a partir del 1 de

${ }^{16}$ Castro Castro, Jalme, Constitución Politica de Colombia, Bogotá, Oveja Negra, 1988. 
febrero en sesiones ordinarias de noventa días. Mientras esto ocurría, seguiría en funciones la Asamblea Nacional.

El acto reformatorio 03, de 30 de marzo de 1905, determinó que por una ley ordinaria se podía cambiar la división del territorio, formando los departamentos que se estimare convenientes para la administración pública.

Asimismo, el acto reformatorio 04, de 30 de marzo de 1905, derogó el artículo 204 de la Constitución, que establecía que toda contribución indirecta o aumento de un impuesto sólo podría cobrarse seis meses después de promulgada la ley que lo creara.

El acto reformatorio 05, de 30 de marzo de 1905, por el cual se eliminaron la vicepresidencia y la designatura y se estableció que al presidente de la República, en caso de falta temporal o absoluta, lo reemplazaría el ministro que designe el Consejo de Ministros; si faltaren los ministros, el gobernador del departamento más cercano a la capital de la república, lo cual se ratificó con el Acto Legislativo 5 de abril 8 de 1909.

Artículo 5. El período presidencial en curso, y solamente mientras esté a la cabeza del gobierno el señor General Reyes, durará una década que se contará del $1^{\circ}$ de enero de 1905 al 31 de diciembre de 1914. En caso de que el poder ejecutivo deje de ser ejercido definitivamente por el señor General don Rafael Reyes, el período presidencial tendrá la duración de cuatro años para el que entre a reemplazarlo de una manera definitiva; esta duración de cuatro años será también para todos los períodos subsiguientes.

El acto reformatorio 06, de 5 de abril de 1905, establecía normas según las cuales nadie en tiempo de paz podía ser privado de su propiedad, salvo excepciones.

También el acto reformatorio 07, de 8 de abril de 1905, ordenaba a las Asambleas Departamentales dirigir y fomentar por medio de ordenanzas y con los recursos propios del Departamento, la instrucción primaria y la beneficencia, la creación de industrias, la colonización de baldíos, la apertura de canales navegables, el arreglo de la policía local y las cárceles del circuito y la fiscalización de las rentas y gastos municipales.

El acto reformatorio 08, de 13 de abril de 1905, fijaba el mismo periodo para senadores y representantes, pero determinaba que los primeros sólo podían ser elegidos por los consejos departamentales.

El acto legislativo 09, de 17 de abril de 1905, estableció que la Constitución podía ser reformada por una Asamblea Nacional convocada expresamente para 
ese objeto por el Congreso, o por el Gobierno Ejecutivo, previa solicitud de la mayoría de las municipalidades. También reglamentó las actividades de dicha Asamblea una vez constituida.

Encontramos también el acto reformatorio 10, de 27 de abril de 1905, que suprimió el Consejo de Estado; el acto legislativo, 01, de 15 de abril de 1907, por el cual se sustituyó el acto legislativo 02 de 1905 (período del Congreso); el acto legislativo 02, del 27 de abril de 1907, por medio del cual se reformaron los artículos 183, 184 y 189 y se creó en cada departamento un Consejo Administrativo, que sustituyó a la Asamblea Departamental; el acto legislativo 01, del 6 de agosto de 1908, por medio del cual se sustituyeron los artículos 93, 99 y 178 de la Constitución y el Acto Legislativo número 8 de 1905, integración del Senado, supresión de los Consejos Administrativos, restitución de las Asambleas Departamentales, creación de los Colegios Electorales.

Otros actos son los siguientes:

- Acto legislativo 02, del 12 de agosto de 1908, por el cual se sustituyó el Título 18 de la Constitución Nacional y se derogaron los actos legislativos números 7 de 1905 y 2 de 1907, acerca de la organización departamental.

- Acto legislativo 03, del 14 de agosto de 1908, por el cual se sustituyó el artículo 1 del acto legislativo número 1 de 1907; fijó el primero de febrero como fecha para la reunión de las Cámaras Legislativas.

- Acto legislativo 01, del 29 de marzo de 1909, por el cual se crean los Consejos Administrativos departamentales.

- Acto legislativo, 02, del 31 de marzo de 1909, por el cual se sustituyen los artículos 108 y 109 de la Constitución.

- Acto legislativo 03, del 2 de abril de 1909, por el cual se sustituye el artículo 3 de la Constitución Nacional, nuevos límites de la República.

- Acto legislativo 04, del 7 de abril de 1909, por el cual se determina el período de duración de las sesiones ordinarias del Congreso Nacional y el período de elección de los congresistas.

- Acto legislativo 05, del 8 de abril de 1909, por el cual se reforma el señalado con el número 5 del 30 de marzo de 1905; orden sucesoral del presidente asignado a los ministros por orden de precedencia y a los gobernadores, por orden de cercanía a la capital de la República.

- Acto legislativo 01, del 28 de mayo de 1910, por el cual se interpreta el artículo 6 del acto legislativo número 9 de 17 de abril de 1905.

- Acto legislativo 02, del 6 de junio de 1910, reformatorio de la Constitución Nacional; supresión de la vicepresidencia de la República. 
- Acto legislativo 03, del 31 de octubre de 1910, reformatorio de la Constitución Nacional.

- Acto reformatorio de la Constitución del 10 de septiembre de 1914, por el cual se restablece el Consejo de Estado.

- Acto legislativo 1, del 27 de agosto de 1918, por el cual se sustituye el artículo 44 de la Constitución.

- Acto legislativo 1, del 18 de octubre de 1921, por el cual se sustituye el acto legislativo 1 de 1918.

- Acto legislativo 1, del 25 de agosto de 1924, por el cual se sustituye el artículo 35 del acto legislativo 3 de 1910.

- Acto legislativo 1, del 20 de noviembre de 1930, reformatorio de la Constitución; composición de las cámaras legislativas.

- Acto legislativo 1, del 5 de agosto de 1931, reformatorio de la Constitución, sobre servicio de notariado y registro.

- Acto legislativo 1, del 8 de septiembre de 1932, sustitutivo del acto 1 de 1921.

- Acto legislativo 1, del 5 de agosto de 1936, reformatorio de la Constitución.

- Acto legislativo 1, del 25 de mayo de 1938, reformatorio de la Constitución.

- Acto legislativo 1, del 19 de septiembre de 1940, reformatorio de la Constitución; jurisdicción del trabajo.

- Acto legislativo 2, del 31 de octubre de 1940, reformatorio de la Constitución.

- Acto legislativo 1, del 12 de febrero de 1943, reformatorio de la Constitución Nacional.

- Acto legislativo 1, del 30 de noviembre de 1944, reformatorio de la Constitución Nacional, sobre la creación del departamento del Chocó.

- Acto legislativo 1, del 16 de febrero de 1945, reformatorio de la Constitución Nacional.

- Acto legislativo 1, del 23 de diciembre de 1946, reformatorio de la Constitución Nacional.

- Acto legislativo 1, del 7 de diciembre de 1947, por el cual se modifican los artículos 51 y 56 del acto legislativo 1 de 1945.

- Acto legislativo 1, del 9 de diciembre de 1952, sobre convocatoria de una Asamblea Nacional Constituyente y regulación de su funcionamiento.

- Acto legislativo 1, del 18 de junio de 1953, por el cual se reforman algunas disposiciones de la Constitución Nacional y el acto legislativo 1 de 1952. 
- Acto legislativo 1, del 30 de julio de 1954, reformatorio de la Constitución Nacional.

- Acto legislativo 2, del 24 de agosto de 1954, reformatorio de la Constitución Nacional, por el cual se dictan unas disposiciones transitorias sobre funciones legislativas de la Asamblea Nacional Constituyente, se crean consejos administrativos para el régimen departamental y municipal, se señalan sus atribuciones y se dictan otras disposiciones.

- Acto legislativo 3, del 27 de agosto de 1954, reformatorio de la Constitución nacional, por el cual se le otorga a la mujer el derecho del sufragio activo y pasivo.

- Acto legislativo 4, del 27 de agosto de 1954, por el cual se dicta una disposición sobre curules vacantes en la Asamblea Nacional Constituyente.

- Acto legislativo 5, del 31 de agosto de 1954, por el cual se confieren unas autorizaciones sobre la creación de establecimientos públicos.

- Acto legislativo 6, del 14 de septiembre de 1954, reformatorio de la Constitución Nacional, por el cual se decreta la prohibición del comunismo internacional.

- Acto legislativo 1, del 3 de noviembre de 1956, reformatorio de la Constitución Nacional, sobre ampliación de la Asamblea Nacional Constituyente.

- Acto legislativo 1, del 22 de marzo de 1957, por el cual se convoca una nueva Asamblea Nacional Constituyente y legislativa, se reforma el acto legislativo 2 de 1954, se dan unas autorizaciones al gobierno y se dictan otras disposiciones.

- Decreto legislativo 0247, del 4 de octubre de 1957, sobre plebiscito para una reforma constitucional.

- Decreto legislativo 0251, del 9 de octubre de 1957, por el cual se sustituye el artículo 12 del texto indivisible sobre reforma a la Constitución Nacional, sometido a plebiscito mediante el decreto legislativo 0247 de 1957.

- Acto legislativo 1, del 15 de septiembre de 1959, reformatorio de la Constitución Nacional, sobre la alternación de los partidos en el poder.

- Acto legislativo 2, del 15 de septiembre de 1959, reformatorio de la Constitución sobre la erección del departamento del Meta.

- Acto legislativo 3, del 24 de diciembre de 1959, por medio del cual se modifica el artículo 7 de la Constitución Nacional.

- Acto legislativo 4, del 24 de diciembre de 1959, por el cual se modifican los artículos 93 y 99 de la Constitución. 
- Acto legislativo 1, del 10 de diciembre de 1960, por el cual se modifica el artículo 121 de la Constitución Nacional.

- Acto legislativo 1, del 28 de diciembre de 1963, por el cual se autoriza erigir en departamento la intendencia de la Guajira.

- Acto legislativo 1, del 12 de diciembre de 1968, por el cual se reforma la Constitución Política de Colombia.

- Acto legislativo 1, del 18 de diciembre de 1975, por el cual se modifican los artículos 14, 15 y 171 de la Constitución Nacional.

- Acto legislativo 1, del 11 de febrero de 1977, por el cual se subrogan los artículos 98, 124, 125, 127 y 128 de la Constitución Nacional.

- Acto legislativo 2, del 19 de diciembre de 1977, por el cual se reforma la Constitución Nacional y se convoca la llamada Pequeña Constituyente.

- Acto legislativo 1, del 4 de diciembre de 1979, por el cual se reforma la Constitución Nacional. Declarado inexequible por la Corte Suprema de Justicia.

- Acto legislativo 1, del 14 de enero de 1981, por el cual se autoriza erigir en departamento la intendencia del Caquetá y se modifica el artículo 83 de la Constitución Nacional.

- Acto legislativo 1, del 10 de noviembre de 1983, por medio del cual se reforma el artículo 113 de la Constitución Nacional.

- Acto legislativo 1, del 9 de enero de 1986, por el cual se reforma la Constitución Política e incorpora la elección popular de alcaldes y las consultas municipales.

- Acto legislativo 1, del 3 de noviembre de 1987, por el cual se erige a Cartagena de Indias en Distrito Turístico y Cultural.

- Acto legislativo 2, del 11 de diciembre de 1987, por el cual se reforma el artículo 183 de la Constitución Política.

- Acto legislativo 1, del 26 de diciembre de 1989, por el cual se autoriza al legislador para erigir en Departamento a la Intendencia del Putumayo.

- Acto legislativo 2, del 29 de diciembre de 1989, por el cual se autoriza a erigir en Departamento la Intendencia de Arauca.

- Acto legislativo 3, del 29 de diciembre de 1989, por el cual se erige a Santa Marta en Distrito Turístico, Cultural e Histórico.

Así reseñamos el numeroso conjunto de 74 reformas a la Carta de 1886, que en su momento, luego de más de cien años de vigencia, motivó su enmienda total a manos de la Asamblea Nacional Constituyente de 1991. Este capítulo 
finaliza con un paralelo entre la Constitución de 1886 y la actual Constitución Política de Colombia de $1991 .{ }^{17}$

\begin{tabular}{|l|l|l|}
\hline \multicolumn{1}{|c|}{ Aspectos } & \multicolumn{1}{|c|}{ Constitución de 1886 } & \multicolumn{1}{c|}{ Constitución de 1991 } \\
\hline 1. Gobierno & Unitario centralista & Unitario descentralizado \\
\hline 2. Derechos & $\begin{array}{l}\text { No consagra } \\
\text { mecanismos de defensa }\end{array}$ & $\begin{array}{l}\text { Los consagra todos. Es una } \\
\text { Constitución garantista }\end{array}$ \\
\hline 3. Soberanía & La nación & El pueblo \\
\hline 4. Democracia & Representativa & Participativa (semidirecta) \\
\hline $\begin{array}{l}\text { 5. Orientación } \\
\text { filosófica }\end{array}$ & Teocrática & Liberal democrática \\
\hline $\begin{array}{l}\text { 6. Clase de Estado } \\
\text { 7. Clase de } \\
\text { Constitución }\end{array}$ & Estado de derecho & Estado social de derecho \\
\hline $\begin{array}{l}\text { 8. Reforma de la } \\
\text { Constitución }\end{array}$ & $\begin{array}{l}\text { Sólo el Congreso } \\
\text { a través de Acto } \\
\text { Legislativo. }\end{array}$ & $\begin{array}{l}\text { El Congreso por Acto } \\
\text { Legislativo. } \\
\text { La Asamblea Constituyente. } \\
\text { El pueblo por referendo. }\end{array}$ \\
\hline
\end{tabular}

En el siglo xx las cosas no se apartaron de la tradición, pues luego de una relativa tregua entre 1910 y 1945, la política estuvo marcada por la violencia. "Bajo las formas del conservatismo tradicional, agrario y católico de un lado y del liberalismo modernizante, urbano y anticlerical del otro. El fervor de estas pasiones dejó más de 200000 muertos en los enfrentamientos de mediados de siglo conocidos como La Violencia". ${ }^{18}$

En conclusión, fueron 104 años, 10 meses y 29 días de la Constitución Nacional Colombiana de 1886, que sigue siendo añorada por su simpleza en la redacción, pero, asimismo, por la intemperancia del sistema centralista, confesional, autoritario, de castas y excluyente del pluralismo. Ese era el momento congruente de la Constitución. Hoy, pese a sus excesos, así como

\footnotetext{
${ }^{17}$ GutiérRez Grisales, Jaime, "La Constitución Política de 1991: Quince años después", Criterio Libre Jurídico, vol. 3, núm. 1, p. 47.

${ }^{18}$ Garcia Villegas, Mauricio, "Estado, derecho y crisis en Colombia", en Pluralismo, Tolerancia, Conflicto, Bogotá, Universidad de La Sabana, 2002, p. 155.
} 
a la violencia que produjo (más que la misma constitución de 1863 que la antecedió), es recordada por haber acrecentado los odios sectaristas que aún están por resolverse.

\section{Bibliografía}

Acevedo Restrepo, Delfín, La Constitución Nacional y sus principales reformas, Bogotá, ESAP, 1986.

Antecedentes de la Constitución Colombiana de 1886. Tomo VIII Complementario de la Historia Extensa de Colombia, Academia Colombiana de Historia, Bogotá, Plaza y Janés, 1988.

Betancur Cuartas, Belisario, "El Día de la Constitución", en Antecedentes de la Constitución de Colombia de 1886. Historia Extensa de Colombia, complemento, Bogotá, Ediciones de la Academia Colombiana de Historia - Plaza y Janés, 1988. Cacua Prada, Antonio, Los Símbolos Patrios, Bogotá, Academia Colombiana de Historia, 1999.

Castro Castro, Jaime, Constitución Politica de Colombia, Bogotá, Oveja Negra, 1988. Ceballos Gómez, Diana, Desde la formación de la República hasta el Radicalismo Liberal (1830-1886), en Luis Enrique Rodríguez, Ricardo Arias, Carlos Uribe, Ana Laura Rodríquez, et al., Historia de Colombia. Todo lo que hay que saber, Bogotá, Taurus, 2010.

ESPAÑA, GonZALO, La guerra civil de 1885. Núñez y la derrota del radicalismo, Bogotá, El Áncora Editores, 1985.

García Valencia, Julio César, Historia de Colombia, Colombia, Asamblea Departamental de Antioquia, 1994.

García Villegas, Mauricio, "Estado, derecho y crisis en Colombia", en Pluralismo, Tolerancia, Conflicto, Bogotá, Universidad de La Sabana, 2002.

Gnecco Mozo, José, La Reforma Constitucional de 1936, Bogotá, Editorial ABC, 1938. GutiérRez Grisales, Jaime, "La Constitución Política de 1991: Quince años después",

Criterio Libre Jurídico, vol. 3, núm. 1.

López Medina, Diego Eduardo, El Derecho de los Jueces, Bogotá, Legis - Universidad de los Andes, 2006.

Melo, Jorge Orlando, Historia minima de Colombia, México, El Colegio de México -

Turner, 2017.

Ocampo López, Javier, ¿Qué es el Conservatismo Colombiano? Bogotá, Planeta, 1991. Pombo, Manuel y Guerra, José Joaquín, Constituciones de Colombia, tomo 4, Colombia, Fondo de Promoción de la Cultura del Banco Popular, 1986.

Rivadeneira Vargas, Antonio José, Historia Constitucional de Colombia 1510-1978, Bogotá, Horizontes, 1978.

Valderrama Andrade, Carlos, Miguel Antonio Caro y la Regeneración, Bogotá, Instituto Caro y Cuervo, 1997. 